\title{
Time for the Transition
}

\author{
Libby V. Morris ${ }^{1}$
}

Published online: 13 December 2019

(C) Springer Nature B.V. 2019

In summer 2003, volume 27, I wrote my first editorial for Innovative Higher Education, and I reiterated the goals of the journal and made a few suggestions to continue its successful path forward. It is now entering the 45th year of publication. Over the years the journal has expanded in the number of issues per volume (from 4 to 6), page length, impact, and reach. Now articles are downloaded from sites around the world. As implied, like the rest of the industry, the journal's publication has moved from hardcopy-only to a combination of online and hardcopy, with the latter falling far behind online readership. While new topics have emerged through the years (e.g., use of twitter, online learning, interdisciplinary education), the journal's goals have remained unchanged: the effect of innovations on teaching and students, a balance between theory and practice, and flexibility in the selection of topics to include provocative new ideas and relevance for action.

The journal launched in 1976, and I followed in the footsteps of long-time editor Dr. Ronald Simpson. His deep expertise in teaching and learning was key to growing and sustaining the journal for 13 years (1989-2002). The editorial hill for me to climb was high, but at my side was Kay Herr Gillespie, who has served as the Associate Editor for the journal for 25 years. She is also Professor Emerita of Colorado State University, and she was the President and long-time Director of the Professional and Organizational Development Network. Her networks and knowledge of higher education, its scholars, and innovative pedagogies are deep.

Kay Gillespie has been more than an Associate Editor; she has been the lodestar for the journal overall. She skillfully matches manuscripts to board members and guest reviewers; she incisively evaluates manuscript topics and their relevance to our readers; and she consistently sets high standards in scholarship, communication, and publishing. Every year authors write to me praising Dr. Gillespie's editorial assistance and her careful attention to detail. It has been a delight to work with Kay and to be the recipient of her great sense of humor and remarkable memory.

The success of the journal primarily rests on the dedication of the editorial review board and the leadership of Dr. Gillespie. The board members review four or more manuscripts each year, and they provide detailed feedback under the blind-review process to the authors. It is not uncommon for an author to write and thank us for a detailed review, even when a manuscript is not accepted for publication.

Libby V. Morris

lvmorris@uga.edu 
Additionally, the quality of a journal can be judged by its editorial board and their involvement in the publication process. Our editorial board members are scholars in their own right, and they give hundreds of hours each year to manuscript reviews. They set high standards for scholarship and give guidance to the interpretation of "innovative" and relevance. Reflecting their commitment to the profession and the journal, several of the current board members have served as Innovative reviewers for over 15 years, including Ann Austin, Paul Diehl, Robert Fitzpatrick, Lion Gardiner, Peter Hoff, Virginia Lee, Peter Ling, and Randy Swing. I extend my gratitude to all board members for their service and commitment to excellence in scholarship.

In my 16 years as editor, I have enjoyed seeing the work of emerging researchers and distinguished scholars appear on the pages of the journal. I have penned over 80 editorials and watched the journal grow in national and international recognition. My role has been challenging and rewarding. After much reflection both Kay and I have decided that it is now time for us to pass the journal on to new leadership. I am pleased to announce that Claire Major, professor and department chair at the University of Alabama, will become the new editor of Innovative Higher Education beginning in 2020. She has served on our editorial review board since 2016 and is an engaged and well-respected thought leader devoted to teaching and learning in higher education and faculty development. I know that Claire will continue to promote excellence, while being a catalyst for creativity and innovation.

It is with mixed emotions that we bid you, our readers, editorial board members, and authors, goodbye and with pleasure and respect that we welcome Claire Major to the editorship of the journal!

Publisher's Note Springer Nature remains neutral with regard to jurisdictional claims in published maps and institutional affiliations. 